\title{
Review
}

\section{Exploring interactions of plant microbiomes}

\author{
Fernando Dini Andreote*, Thiago Gumiere, Ademir Durrer
}

University of São Paulo/ESALQ - Dept. of Soil Science, C.P. 09 - 13418-900 - Piracicaba, SP - Brazil.

*Corresponding author <fdandreo@gmail.com>

Edited by: Paulo Cesar Sentelhas
ABSTRACT: A plethora of microbial cells is present in every gram of soil, and microbes are found extensively in plant and animal tissues. The mechanisms governed by microorganisms in the regulation of physiological processes of their hosts have been extensively studied in the light of recent findings on microbiomes. In plants, the components of these microbiomes may form distinct communities, such as those inhabiting the plant rhizosphere, the endosphere and the phyllosphere. In each of these niches, the "microbial tissue" is established by, and responds to, specific selective pressures. Although there is no clear picture of the overall role of the plant microbiome, there is substantial evidence that these communities are involved in disease control, enhance nutrient acquisition, and affect stress tolerance. In this review, we first summarize features of microbial communities that compose the plant microbiome and further present a series of studies describing the underpinning factors that shape the phylogenetic and functional plantassociated communities. We advocate the idea that understanding the mechanisms by which plants select and interact with their microbiomes may have a direct effect on plant development and health, and further lead to the establishment of novel microbiome-driven strategies, that can cope with the development of a more sustainable agriculture.

Keywords: microbial communities, rhizosphere, endophytes, phyllosphere space in our body" (Lederberg and McCray, 2001). Hence, the human body is a great reservoir of microbes, recently broadly studied by the Human Microbiome project, which linked several features of the host to the presence of specific sets of microbial groups (Turnbaugh et al., 2006; Djikeng et al., 2011; The Human Microbiome Project Consortium, 2012). More recently, the use of this term has been broadly applied to different sets of microbes found in specific hosts or inhabiting a given environment (Boon et al., 2014; Ofek et al., 2014). Boon et al. (2014) proposed that the best definition of 'microbiome' would relate to the set of genes encountered in association with the host or a defined environment, thus diminishing the importance of the link between taxonomy and functionality of the microbial community members. These assumptions made feasible the application of the microbiome concept to plants, which carry out several essential functions in association with distinct microbial groups. Some authors have addressed this issue, such as Bulgarelli et al. (2013), Turner et al. (2013a) and Rout (2014).

In this review article, we focus on the description of plant microbiomes by not only describing the compartments where the microbes live (rhizosphere, endosphere and phyllosphere) but by also discussing the importance of interactions between plants and microorganisms. Due to the availability of data, most examples focus on bacterial fractions of the microbiome or the bacteriome. However, data and discussions on fungal communities are also presented. This review was organized to offer an overview of the plant-associated microbial communities, followed by a description of the role played by plant microbiomes, and finally a portrayal of microbiome-related initiatives underway in Brazil. 


\section{Scientia Agricola}

\section{Plant-associated microbial communities}

The soil matrix is the major reservoir of microbes that interact with plants, being described as the most biodiverse ecosystem on Earth (Vogel et al., 2009). The soil microbiome is responsible for important processes occurring in this environment, which directly relate to plant health. For instance, the soil microbiome suppresses plant diseases by imposing physiological restrictions on pathogens establishing and infecting plant tissues (Weller et al., 2002; Mendes et al., 2011). Equally, the soil microbiome also imparts a certain degree of resistance to the system against "invaders", thereby linking the diversity of the microbiome to its intrinsic ability to restrict or inhibit the survival of exogenous organisms (Elsas et al., 2012).

Although the presence of microbes in plants initially related to the occurrence of diseases, it is now recognized that the vast majority of microbial organisms are not causal agents of damage in plants (Mendes et al., 2013). Several functions have been attributed to microbial cells in close association with plants, for instance, their ability to provide nutrients, such as (i) phosphorus solubilization and nitrogen fixation; (ii) their support of nutrient uptake from the soil, as described for the mycorrhiza; and (iii) their capacity to promote plant protection by hindering agents of plant stresses, such as infection by pathogens and pests (Halmann et al., 1997; Mendes et al., 2011; Mendes et al., 2013; Quecine et al., 2014).

Despite the substantial progress allowed by cultivation-dependent methods, due to "the great plate count anomaly," only a small fraction of the microbes in nature (ca. 1 to $5 \%$ ) are represented by standard cultivation methods for communities retrieved from natural environments (Amann et al., 1995). Hence, an exploration of plant microbiomes that encompasses the whole set of microorganisms interacting with plants might lead to the description of numerous other functions that the associated "microbial tissue" exerts when interacting with the host plant. Some authors claim that a co-evolution process occurs between plants and its associated microbiome, resulting in a strong genomic interdependency, leading to the "metaorganism" concept (Bosch and McFall-Ngai, 2011).

Considering the microbiome as an active component of the host, being also responsive to changes in environmental (biotic and abiotic) conditions, is important to a better understanding of the most important drivers of the composition of plant microbiomes. In order to understand the factors that influence this assembly and the dynamics from a phylogenetic and functional perspective, recent studies have targeted different fractions of the plant microbiome separately. Partitioning the plant microbiome considers three major compartments where microbial cells can establish and develop: the so-called rhizosphere, endosphere and phyllosphere (Hardoim et al., 2008; Hirsch and Mauchline, 2012) (Figure 1). Although the rhizosphere is still a soil portion, it presents a community in part influenced by plant metabolism (Bulgarelli et al., 2013; Philippot et al., 2013), the endo-

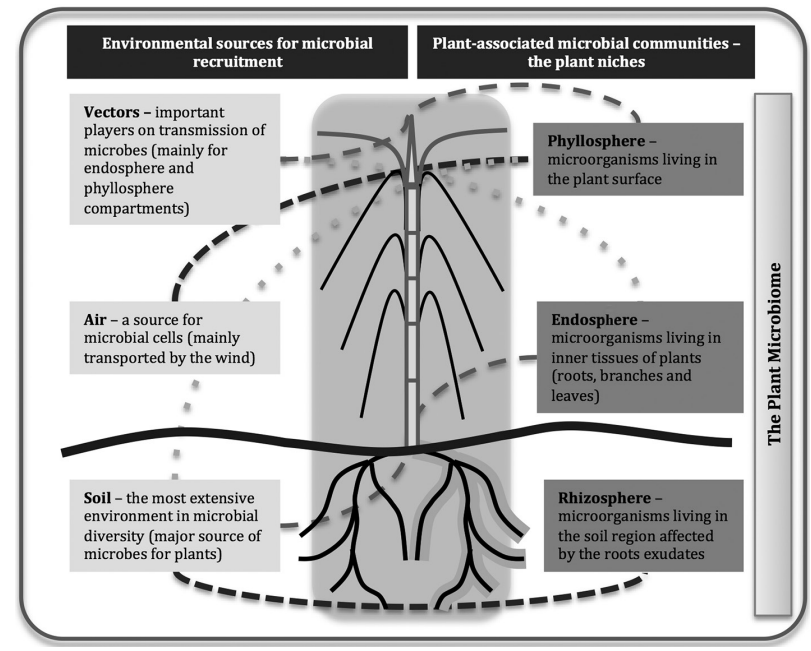

Figure 1 - Schematic representation of the major sources for microbes that compose the plant-associated communities: the rhizosphere, endosphere and phyllosphere. Thickness and fill of connections indicate the contribution of environmental sources for the composition of microbial communities in plant-harboring niches.

sphere is composed of those organisms that intimately interact with the host and inhabit inner plant tissues asymptomatically (Hallmann et al., 1997; Hardoim et al., 2008), and the phyllosphere is defined by microbial cells that are able to colonize plant surfaces (Lambais et al., 2006; Lindow and Brandl, 2003).

The richness of species and diversity of microbial communities that comprise the plant microbiome, as well as the factors affecting it and their performance, are mostly unknown. It is likely that one single plant species has thousands of epiphytic and endophytic microbial species, and the interactions between these microorganisms might regulate several physiological processes in the host. In combination with these factors, the influence of abiotic drivers, such as soil characteristics or the edaphoclimatic area where the plant is cultivated, may play a role. In the following discussion, we characterize each of these "microbial compartments" and provide examples of studies addressing the functional roles of these communities in plant health and development.

\section{Plant selection for the rhizosphere microbial com- munities}

The rhizosphere is defined as the soil region under the influence of the roots (Hiltner, 1904, as cited by Hartmann et al., 2008; Philippot et al., 2013). The microbial community residing in this niche is structured differentially from that found in the bulk soil, which is a difference that is driven by two types of selection: the direct effect of the presence of root exudates, leading to the high availability of nutrients; and the effect of increased microbial biomass, which change the environmental conditions in the rhizosphere. 
As regards the root exudates, the chemical components released in the vicinity of the plant roots are described as belonging to the major groups of carbohydrates, proteins, lipids, phenolic compounds, organic acids and other cellular components (Nguyen, 2003; Dini-Andreote and Elsas, 2013). Among these molecules, some are related to the activation of major fractions of microbial communities (commonly metabolized by most of soil organisms, e.g., glucose), but other compounds released are able to activate specific groups of organisms (those related to signaling and chemotaxis, e.g., flavonoids) (Nguyen, 2003; Jones et al., 2004). These molecules represent the major source of carbon, a nutrient available in abundance to plants through photosynthesis, that is commonly found in limited quantities in the soil environment (when comparing the forms available).

Based on the offering of specific carbon sources, plants trigger a search for organisms that are able to complement the use of carbon sources released from their roots with other nutrients, which are obtained from a variety of metabolic processes found in microbial groups. An example of this need for "metabolic complementation" is the selection of nitrogen-fixing organisms in the rhizosphere. As a highly competitive environment, the rhizosphere is a nitrogen-limited niche, that renders those organisms that are able to capture gaseous nitrogen highly adapted to becoming established and thrive in this niche (Raymond et al., 2004). The availability of nutrients in the rhizosphere results in its colonization by a more abundant microbial community than that found in the bulk soil (Philippot et al., 2013; Prashar et al., 2014).

Secondary selection in the rhizosphere is promoted by the presence of a higher abundance of microbial cells in this niche compared to the bulk soil. The increase in the number of cells per gram of soil leads to variation in local environmental conditions, thereby for example, promoting a decrease in oxygen availability as it is rapidly consumed by the higher microbial biomass (Philippot et al., 2013). This scenario means that other local parameters can also vary, for example, the $\mathrm{pH}$ (commonly lower in the rhizosphere), the organic carbon content (commonly higher in the rhizosphere), and the activity of enzymes produced by microbial cells (Shi et al., 2011).

In summary, taking these effects together, plants have evolved to allow the rhizosphere to attract specific microbes, which support plant development (Mendes et al., 2011; Prashar et al., 2014). This concept is based on the fact that local conditions found in the rhizosphere are interpreted as being optimum environments for the replication of organisms that present features related to the promotion of plant growth, such as uptake of nutrients from non-trivial sources (nitrogen fixation, phosphorus solubilization) or inhibition of pathogen growth (Mendes et al., 2011). As an example of these features, one study isolated several Burkholderia spp. strains from the rhizosphere of sugarcane and observed efficient mechanisms related to the in vitro inhibition of sugarcane pathogen growth, the solubilization of phosphorus, and the production of indole-acetic acid (Luvizotto et al., 2010). However, the combined activity of rhizosphere members is more important to plant development than the role of specific groups in the rhizosphere.

Plant protection against pathogens is one of the most important and least recognized features of the rhizosphere microbial communities. The term 'suppressive rhizosphere' refers to the microbial community that is selected in the rhizosphere and is able to limit the development of pathogens, even in the presence of the host plant. The inability of pathogens to survive is an effect promoted by the biological fraction of the soil (Weller et al., 2002), and the suppressiveness is related to a combinatory activity of several components of the rhizosphere (Mendes et al., 2011). Mendes et al. (2011) demonstrated that the stimulation of antibiotic-producing bacteria in the sugar beet rhizosphere is a major process responsible for the foundation of suppressive soils, exemplified in an experiment where the suppressive soil inhibited the growth of the root pathogen Rhizoctonia solani. This ability to select beneficial organisms in the rhizosphere is believed to be a common feature among plant species, indicating that throughout their evolutionary history, plants have evolved to protect themselves by building their own rhizosphere communities (Cook et al., 1995). This inherent evolutionary capacity was crucial for the establishment of the primitive plant in a terrestrial environment, which has a still undeveloped (adapted to water system) root structure (as revised by Mendes et al., 2013 and Philippot et al., 2013).

Regarding the selection exerted in the rhizosphere, a question that needs to be robustly addressed remains concerning the selection of the taxonomical affiliation of rhizosphere organisms (see Box 1) or their ability to perform specific roles when closely associated with plant roots. Lundberg et al. (2012) targeted this issue and found that the rhizosphere composition varied for the same plant species, according to the available source of microbes in each soil, possibly indicating that the functioning of the rhizosphere components drives the selection of the organisms. However, considering the possibility of high rates of gene transfer in the rhizosphere (check Box 1), it remains to be described how microbial cells that strive under the rhizosphere conditions easily acquire important function-related features.

\section{Endosphere - a niche for intimate friends}

The presence of microbial cells in the inner tissues of plants was long interpreted as being synonymous with plant disease. At that time, the microorganisms found inside plant tissues were those able to infect the plant, leading to losses in plant yield and disturbance of its development. Possibly, this connection was caused by the availability of methods for microbial detection, which were only able to identify an abundance of or easy-to-cultivate microorganisms. 
Box 1 - DNA mobile elements enhancing the genetic drift of features related to plant-associated microorganisms

The traditional view of the link between the taxonomic and functional affiliation of organisms has long been used to target the components and functions of microbial communities in different environments. However, due to their cellular and genomic organization, it seems that microbes (especially bacteria) are much more genotypically unstable than previously believed. The increasing number of complete and draft genome sequences [more than 35,000 genomes as of May 2014 - GOLD database (www.genomesonline.org)] is revealing unique metabolic mechanisms and high genomic variability even within the same "species." This suggests that microbial genomic information is a result of complex interactions, occurring constantly through evolution and also possibly imposed by the local environmental conditions, where they must strive to survive and multiply (Philippot et al., 2010; DiniAndreote et al., 2012).

Most systems described as hotspots for horizontal gene transfer (HGT) are active zones of interactions between different organisms, including both the donor and recipient cells. However, it might be true that the interaction between plants and microbes can also lie in genome re-structuring, in a system where the host can impose local conditions that ultimately select those organisms more susceptible to genetic rearrangement and further acquisition of novel metabolic features. The "easy" occurrence of rearrangements might be linked to the high complexity of microbial communities in the plant boarders (rhizosphere and phyllosphere), where the high abundance of viruses, plasmids and other mobile entities would supply a series of "new weapons" for those microbes to interact with the host plant.

There is evidence that these interactive mechanisms are present and active within the plant microbiome, as well as in different niches in the soil. The first piece of evidence is the high occurrence of transmissible plasmids in the mycosphere (soil region influenced by the fungal hyphae), which carry genes that enable the recipient bacteria to colonize the fungal-driven environment (Zhang et al., 2014). It is likely that something similar is present in the rhizosphere that, furthermore, supplies microbial resources for the host colonization, as evidenced in the manuscript by Tauch et al. (2002) for the cryptic plasmid pIPO2. Possibly, these observations and future studies on this issue will identify the genes (and their derivative organizations) as the units where the selection occurs for the composition of plant-associated microbiomes.
The presence of other (non-pathogenic) organisms inside plants was first described by De Bary (1866), who observed that microbial cells are present in microscopically analyzed plant tissues. This observation remained unexplored until the definition of endophytes arose at the end of the last century. The most common definition of endophytes is based on the ability to detect the microbial cells from previously surface-sterilized plant tissues (Halmann et al., 1997). However, this definition says, in the main, that these organisms are not epiphytes. A working definition for endophytes was provided by Petrini (1991), as "organisms that at some part of their life cycle, colonize internal plant tissues without causing apparent harm to the host." A more detailed analysis of endophytes has divided the endophytic communities into subgroups, named 'obligate' or 'facultative' by the authors. Hardoim et al. (2008) classify as obligate those endophytes that depend on plant metabolism for their survival, being spread amongst plants by vertical transmission or by the activity of vectors. The facultative endophytes are those living outside the host during a certain stage of their life cycle, that are recruited by the plant from adjacent communities, such as the bulk soil, mainly through the rhizosphere.

Endophytes are described as being present in every single plant because it is thought that no plant is free from the presence of such organisms in their inner tissues (Rosenblueth and Martinez-Romero, 2006). The presence of endophytes has even been described in plants maintained in vitro, where these organisms seems to be intimately associated with plants not in terms of colonizing the culture medium but preferring to live inside the plant tissues (Almeida et al., 2009, Abreu-Tarazzi et al., 2010). However, several issues still remain to be better addressed, concerning the roles of endophytes in plant development, and also in understanding the mechanisms governing the transmission of such organisms between plants.

Endophytes are likely to be involved in controlling plant pathogens and promoting plant growth. Mendes et al. (2007) have shown the ability of endophytic Burkholderia spp. to control the growth of the pathogen Fusarium moniliforme. Ferrara et al. (2012) observed that the endophytic diazotrophs from sugarcane roots are able to produce plant growth-promoting substances and to secrete higher amounts of amino acids that might facilitate plant nutrition. Quecine et al. (2014) described the capacity of genetically engineered endophytes producing the heterologous protein cry $1 \mathrm{Ac} 7$ to control the sugarcane pest Diatraea saccharalis. However, although several individual capacities are described in endophytes, it might be suggested that, acting as a community, these organisms are able to perform many other functions not detectable when each microbial group is studied separately. As an example, Araújo et al. (2002) indicated the interactions occurring between the endophytic microbial community and the pathogen Xylella fastidiosa in citrus plants. Araújo et al. (2002) claim that the entire endophytic com- 
munity is affected by the presence of the pathogen and suggest that disease occurrence (in this case, citrus variegated chlorosis) is a result of the interaction between the pathogen $X$. fastidiosa and the endophytic community and not only with the host plant.

The ecology of endophytes is a gap in our knowledge of plant-associated microbes. Several attempts have been made to track the origin of endophytic organisms (Hallmann et al., 1997; Saikkonen et al., 1998; Mitter et al., 2013). Researchers commonly choose the rhizosphere (and consequently the soil) or the seed-born microbial communities as the major sources. Their origin is strictly linked to the strategy of maintenance inside the plants, which determines the dissemination of endophytes between plants. One indicator of the way that specific endophytes interact with plants and evidence of their strategy of survival and transmission is provided by their genome organization.

Dini-Andreote et al. (2012) reviewed several genome sizes and origins, including those of endophytes. These authors correlated the genome size with the lifestyle of bacteria, detecting the variation in environmental conditions as a major driver of genome expansion or shrinking. They suggested that bacteria living in stable environments, such as endosymbionts, commonly have more compact genomes. On the other hand, bacteria living in niches where environmental conditions are constantly shifting, such as soils, would need to harbor a more replete arsenal of genes to thrive under distinct environmental conditions, leading to the prevalence of bigger genomes. At first glance, endophytes seem to fit the first part of this hypothesis because they live inside plants, where the environment is more stable over time compared to the bulk soil. However, considering their origin and transmissions systems, it is possible that some endophytes must address distinct environments during part of the life cycle when they are not hosted by the plant. In fact, Mitter et al. (2013) observed a great variation in the size of genomes of bacterial endophytes. These results suggest that the endophytic community is made up of organisms from distinct origins, with those with larger genomes likely to live in soils (variable environment) and those with smaller genomes likely to be vertically transmitted (stable environment).

\section{Microbial groups living in the phyllosphere}

A third component of the plant microbiome is made of organisms colonizing the external area of aerial plant tissues, the phyllosphere. Although this term can be used for any external surface of plants, it is commonly applied when describing the leaf surface (Vorholt, 2012). The phyllosphere is an enormous environment on Earth that is estimated to reach an area of $6.4 \times 10^{8}$ $\mathrm{km}^{2}$ and is densely colonized by microorganisms (Morris and Kinkel, 2002).

The microbial communities found in the phyllosphere have essential roles in processes related to plant development, for example, performing nitrogen fixation, protecting plants against invading pathogens and biosynthesizing phytohormones (Jones, 1970; Freiberg, 1998; Brandl et al., 2001; Kishore et al., 2005). It makes them important pieces of global processes, such as carbon sequestration (Bulgarelli et al., 2013), and they can be used as potential sources for the development of sustainable agricultural practices.

The phyllosphere community is composed of fungi (filamentous and yeasts), bacteria, algae, and, at lower frequencies, protozoa and nematodes (Lindow and Brandl, 2003). The most abundant group amongst these is the bacterial community, presented in the phyllosphere at numbers between $10^{5}$ and $10^{7}$ cells per $\mathrm{cm}^{2}$ (Beattie et al., 1995; Andrews and Harris, 2000). Phyllosphere-living organisms are able to thrive and live under particular and harsh environmental conditions, characterized as an oligotrophic environment, where there are a limited availability of nutrients and variable conditions of humidity, UV radiation, $\mathrm{pH}$ and temperature (Andrews and Harris, 2000).

Another issue of this theme is the origin of the microbial cells that make up the microbial communities in the phyllosphere. The location of such communities is far from the soil (the main source of plant-associated microbes) and is subjected to high rates of inoculation, promoted in the main, by the activity of vectors and wind (Bullgarelli et al., 2013). Considering these possibilities, together with the limiting and shifting conditions that occur in the phyllosphere, some studies have investigated the major sources of microbial communities in the phyllosphere. Bullgarelli et al. (2013) recently suggested that air and its aerosols, soil and water are the most important sources for microbial cells that make up the communities in the phyllosphere.

It is possible that the assemblage of microbial communities in the phyllosphere is modulated by the interaction of distinct environmental factors. Variations in these conditions might promote the heterogeneity in abundance and structure of the phyllosphere microbial communities in distinct plant species. In tropical (Lambais et al., 2006) and temperate forests (Redford et al., 2010), the plant genotype is a major driver of the composition of the bacterial communities in the phyllosphere. Redford et al. (2010) claim that distinct plant species harbor specific bacterial communities, mainly due to the generation of specific niches and local conditions, which are driven by the genetic, and consequently, the functional metabolism of the plant. The specificity of the phyllosphere community was also observed in plants used in agriculture, with changes observed in the abundance and structure of bacterial communities when comparing beans, cucumber, grasses, lettuce and maize (O'Brien et al., 1989; Kinkel et al., 2000; Rastogi et al., 2012). Geographical distance is also an important player in the structuring of bacterial communities in the phyllosphere (Bokulich et al., 2014). These authors showed that grapevines harbor distinct bacterial communities, which could influence the final quality of the wine produced. 
In a more detailed view, it is possible to observe the occurrence of intra-specific variations in the composition of the microbial community in the phyllosphere. Such variations are driven, in the main, by the nutritional heterogeneity observed in regions on the leaf surface, where the carbon sources (e.g., glucose, fructose and sucrose) are spatially heterogeneous, leading to distinct microbial assemblages on the leaf veins, which are regions near the stomata and surface appendages (Lindow and Brandl, 2003; Vorholt, 2012). In some cases, this heterogeneity is promoted by the organization of microbial cells in biofilms, which are a common feature of organisms in the phyllosphere, acting as an aggregator and protector of the microbial cells under the frequently inhospitable conditions (Davey and O'Toole, 2000; Lindow and Brandl, 2003).

Despite these distinctions, it is possible to observe a "core" for the phyllosphere bacterial community colonizing plants, which is composed of organisms belonging to the phyla Proteobacteria, Actinobacteria, Bacteroidetes and Firmicutes (Redford et al., 2010; Vorholt, 2012). It is worth noting that these phyla (Proteobacteria, Actinobacteria, Bacteroidetes and Firmicutes) are composed of the most abundant and well-studied microorganisms, which indicates that further studies concerning this issue should be designed to evaluate taxonomic ranks below phylum. Hence, this core is believed to be composed of members presenting a co-evolutionary history with plant species, with the host physiology being complementary to the features found within the microbial cells. It remains to be described how this microbial resource can be used for the development of agricultural practices that promote the activity and singular or synergistic relationships that might stimulate plant growth and/or protection against pathogen invasion.

\section{Drivers of plant-associated microbial communities}

Although the plant microbiome can be disentangled into groups of organisms to be studied separately, these distinct groups of organisms respond in similar ways to the drivers underpinning their composition and functioning. Both biotic and abiotic factors impose strong selection on microbial community composition. Special attention has been given to the plant genotype, the phenological stage of the plant, and the use of specific agricultural practices, which ultimately affect the soil physicochemical characteristics.

The plant genotype influences the composition of microbial communities associated with plants through specific metabolic processes (Garbeva et al., 2008; Philippot et al., 2013). A comparative analysis between the endophytic microbial communities of Atriplex canescens and $A$. torreyi, two halophilic plants used as forage in North America, revealed the presence of distinct communities between the two species, mostly differing in the prevalence of diazotrophic bacteria (Lucero et al., 2011). That finding was directly related to the metabolic differences observed between the two plant genotypes, which can also account for changes observed in plants from distinct genotypes within the same species (i.e., varieties, cultivars). Based on that, the differential selection driven by plant genotype has been extensively used to track the safety issues for the cultivation of transgenic plants (Rasche et al., 2006; Cotta et al., 2013; Arpaia et al., 2014), with many studies indicating limited or low effects of the exogenous genes on the plant-associated communities. In contrast to these observations, differences in the composition of microbial communities in the rhizosphere of Arabidopsis thaliana are likely to be determined by soil type, rather than a unique selection by plant genotype (Lundberg et al., 2012). Along the same lines, Yergeau et al. (2014) demonstrated that soil contamination that leads to shifts in community composition ultimately influences the composition of assembled communities in the rhizosphere of willows. In the phyllosphere, which is a niche less subjected to the high density of organism inoculum from soil, the plant genotype seems to exert a stronger selective influence, as observed in specific microbial communities in the phyllosphere of plants living in mangroves (Dias et al., 2012; Rigonato et al., 2012).

As regards the plant developmental stages, shifts observed in plant-associated microbial communities are likely to be related to changes in plant metabolism during the life cycle (Overbeek, L.; Elsas, J.D. 2008; Chaparro et al., 2014). For instance, the developmental stage of maize plants is a stronger driver of the bacterial community composition in the rhizosphere than the soil type and plant genotype (Cotta et al., 2013). Andreote et al. (2010) studied the roles of bacterial inoculation, plant genotype and the developmental stage of the colonization of plant roots (in both rhizosphere and endosphere) by bacterial communities and found the composition of bacterial communities in potato to be mostly driven by the plant genotype (it differed according to the use of distinct varieties) and plant developmental stage (from vegetative to senescent stages). Andreote et al. (2010) also observed that specific fractions of bacterial assemblages, such as the class Alphaproteobacteria and Paenibacillus communities, were influenced, in the main, by the exogenous inoculation of bacterial components into its composition.

Moreover, agricultural practices are also often correlated with changes in the structure of microbial communities associated with plants. That influence occurs based on physical and chemical changes promoted in the soil matrix, ultimately influencing the way by which plants exert the selection of their microbiome. In sugarcane (Saccharum officinarum), soil chemical fertilization alters the composition of bacterial communities in cultivated fields (Wallis et al., 2010). The adoption of distinct agricultural practices was also related to these shifts, where the sugarcane harvesting strategy (burning-based $v s$ mechanical) seems to determine the microbial communities that are selected in soils. Rachid et al. (2013) correlated the differential selection due to the presence 
(or not) of plant residues in the soil, which drastically modulate the degradation of organic matter and other chemical characteristics of the living soil.

In addition to these major drivers, many other environmental conditions can change the composition of plant-associated microbial communities. One of the most promising issues in this field is the mechanism involved in the interaction of the plant microbiome with pathogens. The presence of pathogens can alter the composition of microbial communities in the rhizosphere (Mendes et al., 2011) and in the endosphere (Araújo et al., 2002). Future studies on these topics can lead to information of essential components of plant microbiomes or specific stimuli for beneficial groups that are able to suppress the development of pathogens in plants.

Many researchers have confirmed shifts in microbial communities as being attributable to changes in environmental conditions. However, an open issue is the validation of these inferences made in the taxonomical aspects of plant-associated microbes. The evaluation of changes in the structure of microbial communities is one level where variations might happen. Another issue to consider is related to the specific response of each microbial group in the face of distinct environmental conditions. These responses are related to possible changes in microbial fitness, metabolic response, and even rearrangements at the genomic level. The last possibility most likely constitutes the next barrier to understanding how microbes respond to shifting environmental conditions. This statement is in line with the description of the microbiome by Boon et al. (2014), who considered a set of genes and not a set of organisms to be the best microbiome concept given that these genes might drift between distinct members of the taxonomical components of the microbiome (Box 1). It is reasonable to sug- gest that such stimulation of gene transfer could drive, at least partially, the functional redundancy of soil microbiome.

\section{Studies based on plant microbiomes}

Although plant microbiomes are a broadly studied topic, a holistic view of the microbial groups associated with the entire plant is a recent perspective and still an active area of research. The importance of this subject is evidenced by the growing number of scientific publications on this topic in recent years, as well as research focusing on specific niches of plants and how they modulate their specific microbial communities (Table 1, Figure 2). However, as observed for specific microbial assemblages, it is likely that plant microbiomes vary according to plant species and environmental conditions. In this sense, key questions about how plants acquire their microbiomes, whether certain microorganisms are passed down generation to generation or are recruited from the environment, and the possible composition of the minimal microbiome remain to be answered.

Despite the clear importance of microorganisms in soil nutrient cycling and promotion of plant growth, we still need more comprehensive studies on the interactions between microbial communities that make up the microbiomes of plants. Such an effort would allow for a better understanding of the effects of different environmental conditions and agricultural practices on the proper functioning of plant microbiomes.

Most studies are still to some extent very descriptive or even link the response of the microbiome to shifts in environmental conditions (Table 1). For example, Pinto et al. (2014) reported the microbiome of grape in a vineyard landscape through a culture-independent approach, indicating the occurrence of highly

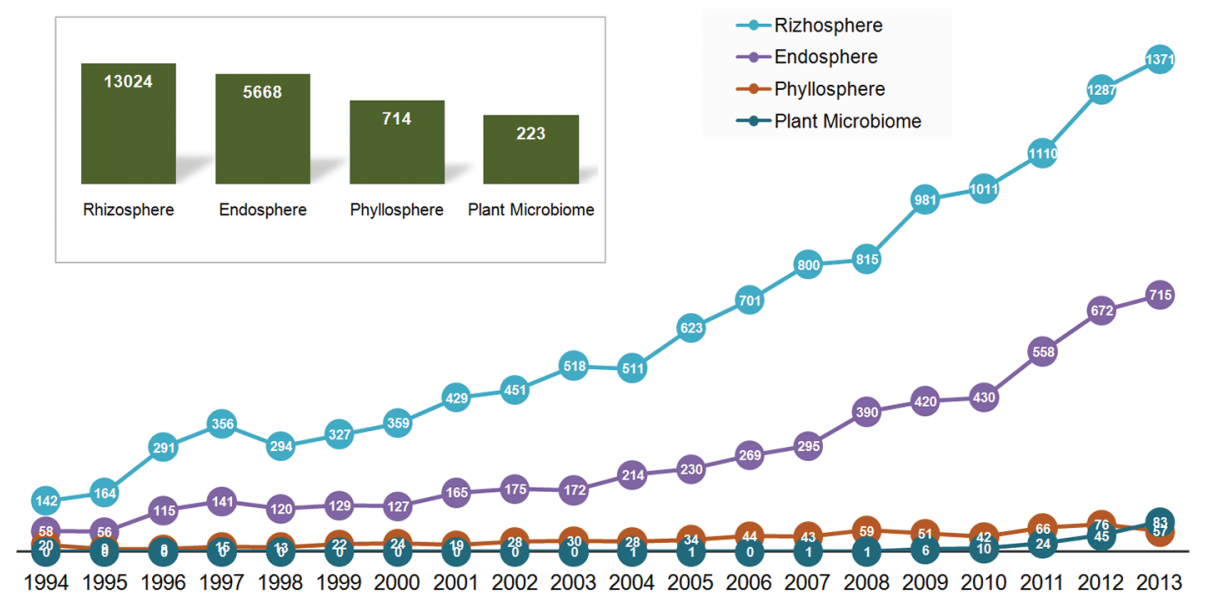

Figure 2 - Numbers of scientific publications on the topics of "plant microbiome," "rhizosphere," "endosphere" and "phyllosphere" in the last 20 years. The small panel (upper-left) represents the number of appearances of each term. Searches were performed in the Scopus database on May 23, 2014. 
Table 1 - Short description of selected papers that represent important advances in the field of plant microbiomes.

\begin{tabular}{|c|c|c|}
\hline Plant & Main findings & Reference \\
\hline Sugar beet (Beta vulgaris L.) & Microbiome-driven protection of plant against attack by a root fungal pathogen. & Mendes et al. (2011) \\
\hline Arabidopsis thaliana & $\begin{array}{l}\text { Influence of the soil on bacterial community assembly in the rhizosphere and } \\
\text { phyllosphere compartments. }\end{array}$ & Lundberg et al. (2012) \\
\hline Arabidopsis thaliana & Correlation between microbial genes and metabolites released by plant roots. & Chaparro et al. (2013) \\
\hline Pepper (Capsicum annuum L.) & $\begin{array}{l}\text { Microbiome selection exerted by plant-roots; enhancing plant photosynthetic activity } \\
\text { and biomass synthesis under drought stress. }\end{array}$ & Marasco et al. (2012) \\
\hline Sarracenia alata & Composition of plant microbiome similar to the gut microbiome of soil microfauna. & $\begin{array}{l}\text { Koopman and Carstens } \\
\text { (2011) }\end{array}$ \\
\hline Cucumber (Cucumis sativus) & $\begin{array}{l}\text { Correlation between the abundance of Massilia and the effects of plant phenological } \\
\text { stage on the root microbiome. }\end{array}$ & Ofek et al. (2011) \\
\hline Balsam Poplar (Populus balsamifera) & Differences in fungal microbiomes promoted by the poplar genotype. & Bálint et al., 2013 \\
\hline Zygophyllum dumosum and Atriplex halimus & Essential role of microbiomes for plant life in the desert. & Kaplan et al. (2013) \\
\hline $\begin{array}{l}\text { Wheat (Triticum aestivum), oat (Avena } \\
\text { sativa) and pea (Pisum sativum) }\end{array}$ & Distinct rhizosphere microbiomes even at high taxonomic rank. & Turner et al. (2013b) \\
\hline Grapevine (Vitis vinifera L.) & Dynamic response of plant microbiome to agrochemical applications. & Pinto et al. (2014) \\
\hline
\end{tabular}

dynamic communities during the plant lifecycle, which was also significantly responsible for the application of agrochemicals. Amongst these studies, a number are already investigating the roles of the associated microbiomes in plant physiology as when describing the microbiome associated with plants living in deserts, where the microbial communities are essential to the resistance of the plant to the unhospitable environment (Kaplan et al., 2013). Marasco et al. (2012) also described the microbiome as an essential component of plant resistance to drought stresses. A more intimate interaction was shown in the study of Chaparro et al. (2013), where the microbiome was responsible for the composition of exudates released by the plant roots. These examples raise the possibility that the selection exerted in the rhizosphere can be driven not only by the plant but, more precisely, by an integrated evolutionary mechanism governed by the nature of the interaction between the host and the associated microbiome.

\section{State of the art in Brazil}

Several Brazilian research groups are accomplished in the study of plant-associated microbial communities, contributing to an important part of the recent literature on the topic (Figure 3). The Brazilian contribution to plant-microbiome research accounts for $4 \%$ of scientific publications on the topic of the plant endosphere. On the topic of the plant microbiome, Brazilian groups account for $3 \%$ of the publications available in the field. Lower percentages that are still significant in absolute numbers are attributed to studies on the rhizosphere and the phyllosphere, with $2 \%$ and $1 \%$ of the literature focusing on these issues, respectively (Figure 3).

In a more detailed view, there is extensive literature generated by Brazilian groups on the topics of community ecology, microbial community structure and diversity, environmental functioning, and plant-associated communities and their implications for agriculture.
Importantly, by combining these topics in an integrative way, substantial understanding is gained for the exploration and preservation of natural areas.

Considering the topic of the microbiome in the actual Brazilian research scenario, a recent initiative aims to organize microbiome-derived data across different Brazilian biomes. The Brazilian Microbiome Project (BMP) (http://www.brmicrobiome.org/) is a group-based effort focused on standardizing the assessment of microbiomes in Brazilian resources (Pylro et al., 2014). In its first publication, the BMP listed the microbiome-based studies under development in Brazil, highlighting the importance of soil microbiomes (in natural and agricultural areas) and plant microbiomes, such as those found in leguminous plants, sugarcane, and plants inhabiting natural areas, such as the Cereus jamacaru, in the Brazilian caatinga (Pylro et al., 2014).

The results generated and organized by the BMP initiative are aimed to be further integrated into a major consortium, named the Earth Microbiome Project (EMP) (http://www.earthmicrobiome.org/). This effort will give the Brazilian microbiomes the opportunity for wider exposure for comparative analyses and determination of particularities in our claimed mega-biodiverse landscape.

\section{Future perspectives}

Although there is increasing information in the literature about host microbiomes, the vast majority is related to the microbial groups in and the human body. The description of the microbiome composition of plants and their putative roles are ongoing themes in research.

Several factors will certainly contribute to the expansion of this approach in the upcoming years. The increasing quality of sampling strategies, DNA extractions, amplifications of target genes from diverse communities, amongst others, represent methodological biases that will certainly diminish over the coming years. Also, the wider access of sequence-based analyses 

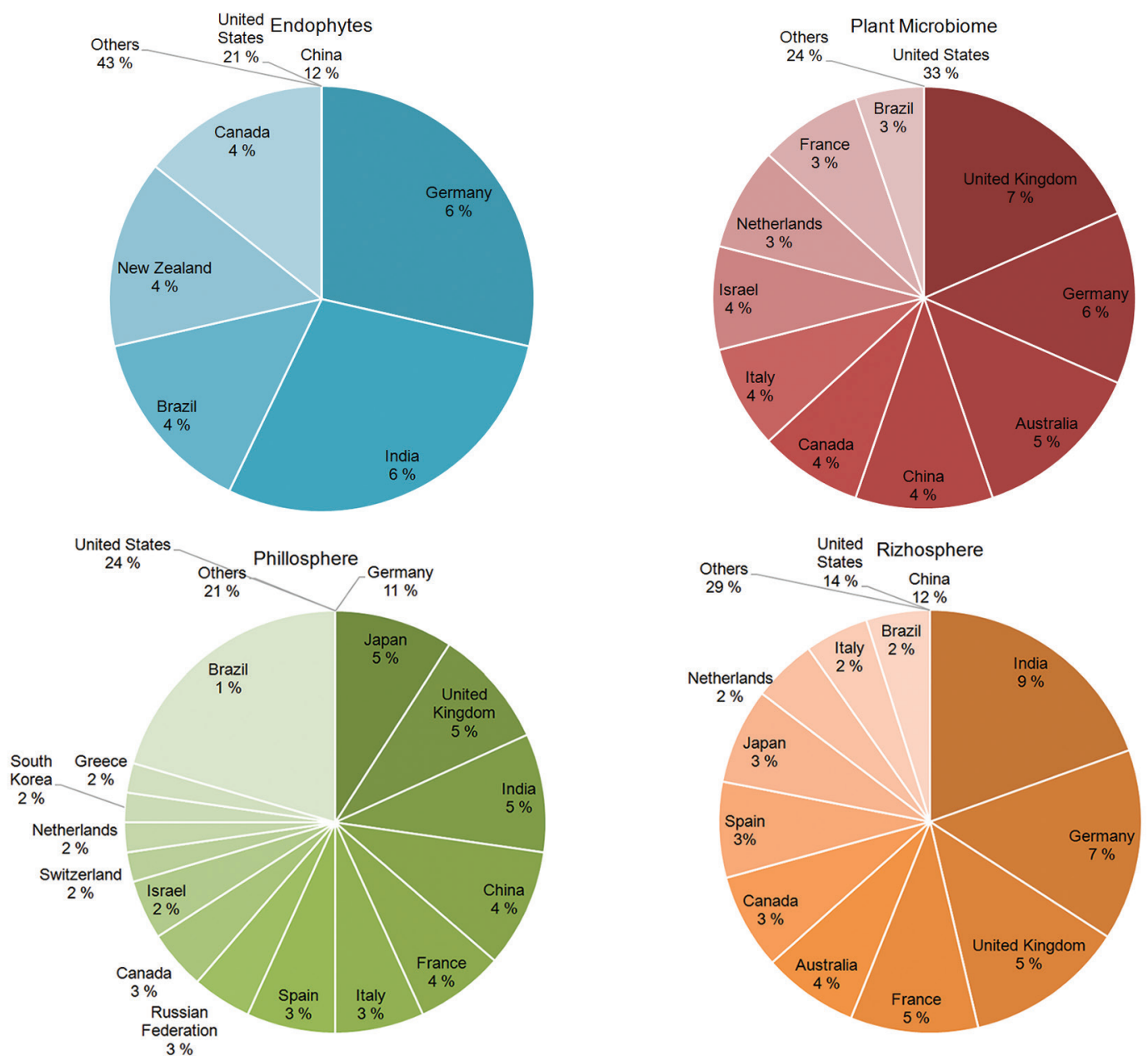

Figure 3 - Distribution of the scientific literature across the most important countries involved in research on plant microbiomes (presenting those with $>1 \%$ of the production on each topic). Data were collected based on the last 20 years of research (i.e., 1994-2013), according to the information available in the Scopus database on May 23, 2014.

allowed by recent advances in DNA sequencing techniques is making possible the sequencing of nucleic acids (DNA or RNA) from great numbers of samples. The recent decrease in sequencing costs and the generation of enormous amounts of data (essential to a characterization of complex microbial communities) have supported the emergence of studies on the microbiome, which is also very dependent on the development of bioinformatics and mathematical modeling. Such technological advances have also provided a more robust description of microbial phylogenetic and taxonomic community composition, thereby increasing the information available in public databases. These developments constitute a breakthrough in our ability to make ecological and functional inferences on microbes in nature (see Box 1). These achievements will surely be complemented by approaches based on more traditional microbiology, as recently shown by Dini-Andreote and Elsas (2013), who indicated the need for ecophysiological insights at an or- ganismal level to unveil the ecological strategies used by microorganisms to survive and thrive in the plant microbiomes. In addition, by combining large amounts of information provided by genomic and other sequencebased studies with new strategies to increase our ability to cultivate and study microbes in the laboratory, we will attain a more detailed understanding of the behavior and functioning of microbiomes in nature.

If plant microbiomes are better described and understood, such information will be available for the development of new technologies, especially those that will focus on a better exploration of the features triggered by microbial cells in agricultural fields. More precisely, it might be possible to alter the microbial community structure, for instance, by inoculation of specific exogenous organisms or by controlling environmental conditions so as to benefit specific sets of these microbiomes, leading to an increase in plant resistance or harnessing of efficiency in the uptake of specific nutrients. In this 
way, the development of so-called "microbiome-driven cropping systems" might result in the next revolution in agriculture, resulting in a more sustainable system for plant production.

\section{Acknowledgments}

The authors would like to acknowledge Francisco Dini-Andreote for the critical and grammatical revision of this manuscript and FAPESP (São Paulo Research Foundation) for the financial support of the studies performed by the group and the grants of students (processes 2011/07343-5 and 2013/18529-8 for A.D and T.G., respectively). CNPq (The National Council for Scientific and Technological Development) is acknowledged for the grant to F.D. Andreote (process 3030034/2011-4).

\section{References}

Abreu-Tarazi, M.F.; Navarrete, A.A.; Andreote, F.D.; Almeida, C.V.; Tsai, S.M.; Almeida, M. 2010. Endophytic bacteria in long-term in vitro cultivated axenic pineapple microplants revealed by PCR DGGE. World Journal of Microbiology and Biotechnology 26: 555-560.

Almeida, C.V.; Andreote, F.D.; Yara, R.; Ossamu, F.A.; Azevedo, J.L.; Almeida, M. 2009. Bacteriossomes in axenic plants: endohytes as stable symbionts. World Journal of Microbiology and Biotechnology 25: 1757-1764.

Amann, R.I.; Ludwing, W.; Schleifer, K.H. 1995. Phylogenetic identification and in situ detection of individual microbial cells without cultivation. Microbiology Reviews 59: 143-169.

Andreote, F.D.; Azevedo, J.L.; Araújo, W.L. 2009. Assessing the diversity of bacterial communities associated with plants. Brazilian Journal of Microbiology 40: 417-432.

Andreote, F.D.; Rocha, U.N.; Araújo, W.L.; Azevedo, J.L.; Overbeek, L.S. van. 2010. Effect of bacterial inoculation, plant genotype and developmental stage on root-associated and endophytic bacterial communities in potato (Solanum tuberosum). Antonie van Leeuwenhoek 97: 389-399.

Andrews, J.H.; Harris, R.F. 2000. The ecology and biogeography of microorganisms on plant surfaces. Annual Reviews of Phytopathology 38: 145-180.

Araújo, W.L.; Marcon, J.; Maccheroni, W.; Elsas, J.D. van; Vuurde, J.W.L. van; Azevedo, J.L. 2002. Diversity of endophytic bacterial populations and their interaction with Xylella fastidiosa in citrus plants. Applied and Environmental Microbiology 68: 4906-4914.

Bálint, M.; Tiffin, P.; Hallström, B.; O'Hara, R.B.; Olson, M.S.; Fankhauser, J.D.; Schmitt, I. 2013. Host genotype shapes the foliar fungal microbiome of balsam poplar (Populus balsamifera). PloS One 8: e53987.

Beattie, G.A.; Lindow, S.E. 1995. The secret life of foliar bacterial pathogens on leaves. Annual Reviews of Phytopathology 33: 145-172.

Bokulich, N.A.; Thorngate, J.H.; Richardson, P.M.; Mills, D.A. 2014. Microbial biogeography of wine grapes is conditioned by cultivar, vintage, and climate. Proceedings of the National Academy of Science of the USA 111: E139-148.

Boon, E.; Meehan, C.J.; Whidden, C.; Wong, D.H.J.; Langille,
M.G.I.; Beiko, R.G. 2014. Interactions in the microbiome: communities of organisms and communities of genes. FEMS Microbiology Reviews 38: 90-118.

Bosch, T.C.; McFall-Ngai, M.J. 2011. Metaorganisms as the new frontier. Zoology Review 114: 185-90.

Brandl, M.T.; Quinones, B.; Lindow, S.E. 2001. Heterogeneous transcription of an indoleacetic acid biosynthetic gene in Erwinia herbicola on plant surfaces. Proceedings of the National Academy of Science of the USA 98: 3454-3459.

Bulgarelli, D.; Spaepen, S.S.; Themaat, E.V.L.; Shulze-Lefert, P. 2013. Structure and functions of the bacterial microbiota of plants. Annual Reviews in Plant Biology 64: 807-838.

Chagnon, P.L.; Bradley, R.L.; Maherali, H.; Klironomos, J.N. 2013. A trait-based framework to understand life history of mycorrhizal fungi. Trends in Plant Science 18: 484-491.

Chaparro, J.M.; Badri, D.V.; Bakker, M.G.; Sugiyama, A.; Manter, D.K.; Vivanco, J.M. 2013. Root exudation of phytochemicals in Arabidopsis follows specific patterns that are developmentally programmed and correlate with soil microbial functions. PloS One 8: e55731.

Chaparro, J.M.; Badri, D.V.; Vivanco, J.M. 2014. Rhizosphere microbiome assemblage is affected by plant development. The ISME Journal 8: 790-803.

Cook, R.J.; Thomashow, L.S.; Weller, D.M.; Fujimoto, D.; Mazzola, M.; Bangera, G.; Kim, D.S. 1995. Molecular mechanisms of defense by rhizobacteria against root disease. Proceedings of the National Academy of Science of the USA 92: 4197-4201.

Cotta, S.R.; Dias, A.C.F.; Marriel, I.E.; Gomes, E.A.; Elsas, J.D. van; Seldin, L. 2013. Temporal dynamics of microbial communities in the rhizosphere of two genetically modified (GM) maize hybrids in tropical agrosystems. Antonie van Leeuwenhoek 103: 589-601.

Davey, M.E.; O'Toole, G.A. 2000. Microbial biofilms: from ecology to molecular genetics. Microbiology and Molecular Biology Reviews 64: 847-867.

De Bary, A. 1866. Morphologie und Physiologie Pilze, Flechten, und Myxomyceten. Hofmeister's Handbook of Physiological Botany. Engelmann, Leipzig, Germany.

Dias, A.C.F.; Taketani, R.G.; Andreote, F.D.; Luvizotto, D.M.; Silva, J.L.; Nascimento, R.S.; Melo, I.S. 2012. Interspecific variation of the bacterial community structure in the phyllosphere of the three major plant components of mangrove forests. Brazilian Journal of Microbiology 43: 653-660.

Dini-Andreote, F.; Andreote, F.D.; Araújo, W.L.; Trevors, J.T.; Elsas, J.D. van. 2012. Bacterial genomes: habitat specificity and uncharted organisms. Microbial Ecology 64: 1-7.

Dini-Andreote, F.; Elsas, J.D. van. 2013. Back to the basics: the need for ecophysiological insights to enhance our understanding of microbial behaviour in the rhizosphere. Plant and Soil 373: 1-15.

Djikeng, A.; Nelson, B.J.; Nelson, K.E. 2011. Implications of the human microbiome research for the developing world. $\mathrm{p}$. 317-336. In: Nelson, K.E. Metagenomics of the human body. Springer New York, NY, USA.

Doornbos, R.F.; Loon, L.C. van; Bakker, P.H.M. 2011. Impact of root exudates and plant defense signaling on bacterial communities in the rhizosphere: a review. Agronomy for Sustainable Development 32: 227-243. 
Elsas, J.D. van; Chiurazzi, M.; Mallon, C.A.; Elhottova, D.; Krištufek, V.; Salles, J.F. 2012. Microbial diversity determines the invasion of soil by a bacterial pathogen. Proceedings of the National Academy of Science of USA 109: 1159-1164.

Ferrara, F.I.S.; Oliveira, Z.M.; Gonzales, H.H.S.; Floh, E.I.S.; Barbosa, H.R. 2012. Endophytic and rhizospheric enterobacteria isolated from sugar cane have different potentials for producing plant growth-promoting substances. Plant and Soil 353: 409417.

Freiberg, E. 1998. Microclimatic parameters influencing nitrogen fixation in the phyllosphere in a Costa Rican premontane rain forest. Oecologia 117: 9-18.

Garbeva, P.; Elsas, J.D. van; Veen, J.A. van. 2008. Rhizosphere microbial community and its response to plant species and soil history. Plant Soil 302: 19-32.

Hallmann, J.; Quadt-Hallmann, A.; Mahaffee, W.F.; Kloepper, J.W. 1997. Bacterial endophytes in agricultural crops. Canadian Journal of Microbiology 43: 895-914.

Hardoim, P.; Overbeek, L. van; Elsas, J. van. 2008. Properties of bacterial endophytes and their proposed role in plant growth. Trends in Microbiology 16: 463-471.

Hartmann, A.; Rothballer, M.; Schmid, M. 2008. Lorenz Hiltner, a pioneer in rhizosphere microbial ecology and soil bacteriology research. Plant and Soil 312: 7-14.

Hirsch, P.R.; Mauchline, T.H. 2012. Who's who in the plant root microbiome? Nature Biotechnology 30: 961-962.

Jones, D.L.; Hodge, A.; Kuzyakov, Y. 2004. Plant and mycorrhizal regulation of rhizodeposition. New Phytologist 163: 459-480.

Jones, K. 1970. Nitrogen fixation in phyllosphere of Douglas Fir Pseudotsuga-Douglasii. Annals of Botany 34: 239-244.

Kaplan, D.; Maymon, M.; Agapakis, C.M.; Lee, A.; Wang, A.; Prigge, B.A.; Hirsch, A.M. 2013. A survey of the microbial community in the rhizosphere of two dominant shrubs of the Negev Desert highlands, Zygophyllum dumosum (Zygophyllaceae) and Atriplex halimus (Amaranthaceae), using cultivation-dependent and cultivation-independent methods. American Journal of Botany 100: 1689-1691.

Kavamura, V.N.; Santos, S.N.; Silva, J.L.; Parma, M.M.; Avila, L.A.; Visconti, A.; Zucchi, T.D.; Taketani, R.G.; Andreote, F.D.; Melo, I.S. 2013. Screening of Brazilian cacti rhizobacteria for plant growth promotion under drought. Microbiological Research 168: 183-191.

Kinkel, L.L.; Wilson, M.; Lindow, S.E. 2000. Plant species and plant incubation conditions influence variability in epiphytic bacterial population size. Microbial Ecology 39: 1-11.

Kishore, G.K.; Pande, S.; Podile, A.R. 2005. Biological control of late leaf spot of peanut (Arachis hypogaea) with chitinolytic bacteria. Phytopathology 95: 1157-1165.

Koopman, M.M.; Carstens, B.C. 2011. The microbial Phyllogeography of the carnivorous plant Sarracenia alata. Microbial Ecology 61: 750-8.

Lambais, M.R.; Crowley, D.E.; Cury, J.C.; Bull, R.C.; Rodrigues, R.R. 2006. Bacterial diversity in tree canopies of the Atlantic forest. Science 312: 1917-1917.

Lederberg, J.; McCray, A.T. 2001. 'Ome Sweet Omics' - a genealogical treasury of words. Scientist 15: 8.

Lindow, S.E.; Brandl, M.T. 2003. Microbiology of the phyllophere. Applied and Environmental Microbiology 69: 1875-1883.
Lucero, M.E.; Unc, A.; Cooke, P.; Dowd, S.; Sun, S. 2011. Endophyte microbiome diversity in micropropagated Atriplex canescens and Atriplex torreyi var Griffiths. PLoS One 6: e17693.

Lundberg, D.S.; Lebeis, S.L.; Paredes, S.H.; Yourstone, S.; Gehring, J.; Malfatti, S.; Tremblay, J.; Engelbrektson, A.; Kunin, V.; Rio, T.G.; Edgar, R.C.; Eickhorst, T.; Ley, R.E.; Hugenholtz, P.; Tringe, S.G.; Dangl, J.L. 2012. Defining the core Arabidopsis thaliana root microbiome. Nature 488: 86-90.

Luvizotto, D.M.; Marcon, J.; Andreote, F.D.; Dini-Andreote, F.; Neves, A.A.C.; Araújo, W.L.; Pizzirani-Kleiner, A.A. 2010. Genetic diversity and plant-growth related features of Burkholderia spp. from sugarcane roots. World Journal of Microbiology and Biotechnology 26: 1829-1836.

Marasco, R.; Rolli, E.; Ettoumi, B.; Vigani, G.; Mapelli, F.; Borin, S.; Daffonchio, D. 2012. A drought resistance-promoting microbiome is selected by root system under desert farming. PloS One 7: e48479.

Mendes, R.; Garbeva, P.; Raaijmakers, J.M. 2013. The rhizosphere microbiome: significance of plant beneficial, plant pathogenic, and human pathogenic microorganisms. FEMS Microbiology Reviews 37: 634-663.

Mendes, R.; Kruijt, M.; Bruijn, I.; Dekkers, E.; Voort, M. van der; Schneider, J.H.M; Piceno, Y.M.; Santis, T.Z.; Andersen, G.L.; Bakker, P.A.H.M.; Raaijmakers, J.M. 2011. Deciphering the rhizosphere microbiome for disease-suppressive bacteria. Science 332: 1097-1100.

Mendes, R.; Pizzirani-Kleiner, A.A.; Araújo, W.L.; Raaijmakers, J.M. 2007. Diversity of cultivated endophytic bacteria from sugarcane: genetic and biochemical characterization of Burkholderia cepacia complex isolates. Applied and Environmental Microbiology 73: 7259-7267.

Mitter, B.; Petric, A.; Shin, M.W.; Chain, P.S.G.; HaubergLotte, L.; Reinhold-Hurek, B.; Nowak, J.; Sessitsch, A. 2013. Comparative genome analysis of Burkholderia phytofirmans PsJN reveals a wide spectrum of endophytic lifestyles based on interaction strategies with host plants. Frontiers in Plant Science 4: 120.

Morris, C. E.; Kinkel, L.L. 2002. Fifty years of phyllosphere microbiology: significant contributions to research in related fields. p. 365-375. In: Lindow, S.E.; Hecht-Poinar, E.I.; Elliott, V., eds. Phyllosphere microbiology. APS Press, St. Paul, MN, USA.

Nguyen, C. 2003. Rhizodeposition of organic C by plants: mechanisms and controls. Agronomie 23: 375-396.

O'Brien, R.D.; Lindow, S.E. 1989. Effect of plant species and environmental conditions on epiphytic population sizes of Pseudomonas syringae and other bacteria. Phytopathology 79: 619-627.

Ofek, M.; Hadar, Y.; Minz, D. 2011. Colonization of cucumber seeds by bacteria during germination. Environmental Microbiology 13: 2794-807.

Ofek, M.; Voronov-Goldman, M.; Hadar, Y.; Minz, D. 2014. Host signature effect on plant root-associated microbiomes revealed through analyses of resident $v s$ active communities. Environmental Microbiology 16: 2157-67.

Overbeek, L. van; Elsas, J.D. van. 2008. Effects of plant genotype and growth stage on the structure of bacterial communities associated with potato (Solanum tuberosum L.). FEMS Microbiology Ecology 64: 283-296. 
Philippot, L.; Andersson, S.G.E.; Battin, T.; Prosser, J.I.; Schimel, J.P.; Whitman, W.B.; Hallin, S. 2010. The ecological coherence of high bacterial taxonomic ranks. Nature Reviews in Microbiology 8: 523-529.

Philippot, L.; Raaijmakers, J.M.; Lemanceau, P.; Putten, W.H. van der. 2013. Going back to the roots: the microbial ecology of the rhizosphere. Nature Reviews Microbiology 11: 789-799.

Pinto, C.; Pinho, D.; Sousa, S.; Pinheiro, M.; Egas, C.; Gomes, A.C. 2014. Unravelling the diversity of grapevine microbiome. PLoS ONE 9: e85622.

Prashar, P.; Kapoor, N.; Sachdeva, S. 2014. Rhizosphere: its structure, bacterial diversity and significance. Reviews in Environmental Science and Bio/Technology 13: 63-77.

Pylro, V.S.; Roesch, L.F.W.; Ortega, J.M.; Amaral, A.M.; Tótola, M.R.; Hirsch, P.R.; Rosado, A.S.; Góes-Neto, A.; Da Silva, A.L.C.; Rosa, C.A.; Morais, D.K.; Andreote, F.D.; Duarte, G.F.; Melo, I.S.; Seldin, L.; Lambais, M.R.; Hungria, M.; Peixoto, R.S.; Kruger, R.H.; Tsai, S.M.; Azevedo, V. 2014. Brazilian Microbiome Project: revealing the unexplored microbial diversity challenges and prospects. Microbial Ecology 67: 237241.

Quecine, M.C.; Araujo, W.L.; Tsui, S.; Parra, J.R.P.; Azevedo, J.L.; Pizzirani-Kleiner, A.A. 2014. Control of Diatraea saccharalis by the endophytic Pantoea agglomerans 33.1 expressing cry1Ac7. Archives of Microbiology 196: 227-234.

Rachid, C.T.C.C.; Santos, A.L.; Piccolo, M.C.; Balieiro, F.C.; Coutinho, H.L.C.; Peixoto, R.S.; Tiedje, J.M.; Rosado, A.S. 2013. Effect of sugarcane burning or green harvest methods on the Brazilian Cerrado soil bacterial community structure. Plos One 8: e59342.

Rasche, F.; Hodl, V.; Poll, C.; Kandeler, E.; Gerzabek, M.H.; Elsas, J.D. van; Sessitsch, A. 2006. Rhizosphere bacteria affected by transgenic potatoes with antibacterial activities compared with the effects of soil, wild-type potatoes, vegetation stage and pathogen exposure. FEMS Microbiology Ecology 56: 219-235.

Rastogi, G.; Sbodio, A.; Tech, J.J.; Suslow, T.V.; Coaker, G.L.; Leveau, J.H.J. 2012. Leaf microbiota in an agroecosystem: spatiotemporal variation in bacterial community composition on field-grown lettuce. The ISME Journal 6: 1812-1822.

Raymond, J.; Siefert, J.L.; Staples, C.R.; Blankenship, R.E. 2004. The natural history of nitrogen fixation. Molecular Biology and Evolution 21: 541-554.

Redford, A.J.; Bowers, R.M.; Knight, R.; Linhart, Y.; Fierer, N. 2010. The ecology of the phyllosphere: geographic and phyllogenetic variability in the distribution of bacteria on tree leaves. Environmental Microbiology 12: 2885-2893.

Rigonato, J.; Alvarenga, D.O.; Andreote, F.D.; Dias, A.C.F.; Melo, I.S.; Kent, A.; Fiore, M.F. 2012. Cyanobacterial diversity in the phyllosphere of a mangrove forest. FEMS Microbiology Ecology 80: 312-322

Rosenblueth, M.; Martinez-Romero, E. 2006. Bacterial endophytes and their interactions with hosts. Molecular Plant-Microbe Interactions 19: 827-837.

Rout, M.E. 2014. The plant microbiome. Genomes of Herbaceous Land Plants 69: 279-309.
Saikkonen, K.; Faeth, S.H.; Helander, M.; Sullivan, T.J. 1998. Fungal endophytes: a continuum of interactions with host plants. Annual Review of Ecology and Systematics 29: 319-343.

Shi, J.Y.; Yuan, X.F.; Lin, H.R.; Yang, Y.Q.; Li, Z.Y. 2011. Differences in soil properties and bacterial communities between the rhizosphere and bulk soil and among different production areas of the medicinal plant Fritillaria thunbergii International Journal of Molecular Sciences 12: 3770-3785.

Tauch, A.; Schneiker, S.; Selbitschka, W.; Puhler, A.; Overbeek, L.S. van; Smalla, K.; Thomas, C.M.; Bailey, M.J.; Forney, L.J.; Weightman, A.; Ceglowski, P.; Pembroke, T.; Tietze, E.; Schroder, G.; Lanka, E.; Elsas, J.D. van. 2002. The complete nucleotide sequence and environmental distribution of the cryptic, conjugative, broad-host-range plasmid pIPO2 isolated from bacteria of the wheat rhizosphere. Microbiology 148: 1637-1653.

The Human Microbiome Project Consortium. 2012. Structure, function and diversity of the healthy human microbiome. Nature 486: 207-214.

Turnbaugh, P.J.; Ley, R.E.; Mahowald, M.A.; Magrini, V.; Mardis, E.R.; Gordon, J.I. 2006. An obesity-associated gut microbiome with increased capacity for energy harvest. Nature 444: 1027103.

Turner, T.R.; James, E.K.; Poole, P.S. 2013a. The plant microbiome. Genome Biology 14: 209.

Turner, T.R.; Ramakrishnan, K.; Walshaw, J.; Heavens, D.; Alston, M.; Swarbreck, D.; Poole, P.S. 2013b. Comparative metatranscriptomics reveals kingdom level changes in the rhizosphere microbiome of plants. The ISME Journal 7: 22482258.

Vogel, T.M.; Simonet, P.; Jansson, J.K.; Hirsch P.R.; Tiedje, J.M.; Elsas, J.D. van; Bailey, M.J.; Nalin, R.; Philippot, L. 2009. TerraGenome: a consortium for the sequencing of a soil metagenome. Nature Reviews in Microbiology 7: 252.

Vorholt, J.A. 2012. Microbial life in the phyllosphere. Nature Reviews 10: 828-840.

Wallis, P.D.; Haynes, R.J.; Hunter, C.H.; Morris, C.D. 2010. Effect of land use and management on soil bacterial biodiversity as measured by PCR-DGGE. Applied Soil Ecology 46: 147-150.

Weller, D.M.; Raaijmakers, J.M.; Gardener, B.B.M.; Thomashow, L.S. 2002. Microbial populations responsible for specific soil suppressiveness to plant pathogens. Annual Reviews of Phytopathology 40: 309-348.

Yergeau, E.; Sanschagrin, S.; Maynard, C.; St-Arnaud, M.; Greer, C.W. 2014. Microbial expression profiles in the rhizosphere of willows depend on soil contamination. The ISME Journal 8: 344-358.

Zhang, M.; Silva, M.C.P.; Mares, M.C.; Elsas, J.D. van. 2014. The mycosphere constitutes an arena for horizontal gene transfer with strong evolutionary implications for bacterial-fungal interactions. FEMS Microbiology Ecology DOI: http://dx.doi. org/10.1111/1574-6941.12350. 